\title{
LA «CORONA RADIATA» DE HeLIOS-SOL COMO SÍMBOLO DE PODER EN LA CULTURA VISUAL ROMANA
}

\author{
The Corona Radiata of Helios-Sun \\ AS THE SYMBOL OF POWER \\ in the Roman Visual Culture
}

\author{
Jorge TOMÁs García*
}

Instituto de História da Arte, FCSH, Universidade NOVA Lisboa

Recibido: 21/03/2017 Evaluado: 24/04/2017 Aprobado: 04/07/2017

RESUMEN: El presente trabajo pretende analizar la presencia del motivo iconográfico de la corona radiata en la cultura visual romana como símbolo de poder. Para ello, analizaremos la figura mitológica de Helios, y sus múltiples variantes en las fuentes clásicas, especialmente aquellas que más la relacionan con la divinidad del Sol en el mundo romano. Las principales categorías de interpretación de la iconografía del Sol en la cultura visual romana enriquecen las variantes iconológicas de la presencia de la corona radiata. Así, pretendemos analizar la naturaleza real o simbólica de este atributo iconográfico tan presente desde la época de Augusto como símbolo de poder y luz ligado a la regalía imperial.

Palabras clave: Helios, Sol, corona radiata, cultura visual, luz.

ABSTRACT: This article aims to analyze the presence of the iconographic motif of the corona radiata in the Roman visual culture as a symbol of power. For this, we will analyze the mythological figure of Helios,

\footnotetext{
* Este trabajo está financiado por fondos nacionales a través de la FCT - Fundação para a Ciência e a Tecnologia en el marco del proyecto SFRH/BPD/99633/2014, y en el contexto del Grupo de Investigación de Excelencia Estudios Visuales (Fundación Séneca, 19905/GERM/15). Rua do Garrido 75, 1. d, 1900-248, Lisboa (Portugal). jgarcia@fcsh.unl.pt. +34 627036631. Instituto de História da Arte (FCSH/NOVA Lisboa).
} 
and its multiple variants in the classical sources, especially those that relate more to the divinity of the Sun in the Roman world. The main categories of interpretation of the Sun's iconography in the Roman visual culture enrich the iconological variants of the presence of the corona radiata. Thus, we intend to analyze the real or symbolic nature of this iconographic attribute so present since the time of Augustus as a symbol of power and light linked to the imperial realia.

Keywords: Helios, Sun, corona radiata, visual culture, light.

\section{Helios EN LA Mitología SOLAR GRIEGA}

En las fuentes griegas Helios es hijo de Hiperión (o Hyperionion ${ }^{1}$ ) y Tea, y Ehermano de Selene y Eos. ${ }^{2}$ Homero describe a Helios como el encargado de dotar de luz tanto a los dioses como a los hombres: sale por el este del océano, aunque no desde un río, sino del lago Limne, se eleva al cielo, donde alcanza el punto más alto a la hora del mediodía, y luego desciende, para ponerse por la noche en la oscuridad del oeste. ${ }^{3}$ Algunos poetas posteriores embellecieron esta idea: describieron un magnífico palacio en el este, donde Helios ocupaba un trono, rodeado por las personificaciones de las diferentes divisiones del tiempo (Ov. Met. II. 1); y mientras Homero cita las puertas de Helios en el oeste, las fuentes posteriores le asignan un segundo palacio en el oeste, y describen sus caballos alimentándose de hierbas que crecen en las islas de los Bienaventurados. ${ }^{4}$ Los puntos en los que Helios se eleva y desciende en el océano son diferentes según las estaciones del año; los puntos extremos en el norte y el sur, entre los cuales toma salida y puesta del lugar, son los tropai êelioio (Od. XV. 403; Hes. Op. et Dies, 449, 525). La manera en que Helios pasa durante la noche del oeste al océano oriental no se menciona ni en Homero ni en Hesíodo, pero más tarde las fuentes lo hacen navegar en un barco de oro, obra de Hefesto. ${ }^{5}$ Los caballos y el carro con el que Helios recorre diariamente

1. Hom. Od. XII. 176, Hymn. in Cer. 74; Hes. Theog. 1011; Hom. Od. I. 24, II. 19, 398, Hymn. in Apoll. Pyth. 191. Para un resumen útil de las fuentes, P. MATERn: Helios und Sol. Kulte und Ikonographie des griechischen und römischen Sonnengottes, Estambul, 2002, pp. 9-19 (incluye fuentes también de cronología romana). W. FaUth: «Helios Megistos. Zur synkretistischen Theologie der Spätantike», Religions in the Graeco-Roman World 125, Leiden, 1995, XVII-XXXIII, da una excelente visión general de las funciones de Helios en la cultura griega con mayor énfasis en la filosofía. Para el culto de Helios de Rodas, H. ZusANEK: Rhodos und Helios: Mythos, Topos und Kultentwicklung, Fráncfort del Meno, 1994.

2. Hom. Od. XII. 176, 322, Hymn. in Min. 9, 13; Hes. Theog. 371.

3. Hom. Il. VII. 422, Od. III. 1, 335, IV. 400, X. 191, XI. 18, XII. 380.

4. Nonn. Dionys. XII. 1; Athen. VII. 296; Stat. Theb. III. 407.

5. Athen. XI. 469; Apollod. II. 5. 10. 
el mismo trayecto no se mencionan ni en la Ilíada ni en la Odisea, si bien es descrito posteriormente de manera minuciosa. ${ }^{6}$

Helios es descrito en los poemas homéricos como el dios que ve y oye todas las cosas, pero, a pesar de esto, no es consciente, por ejemplo, de percibir cómo los compañeros de Ulises robaron sus bueyes (Od. XII, 375). Sin embargo, debido a su omnisciencia, fue capaz de confesar a Hefesto la infidelidad de Afrodita, y revelar a Deméter el rapto de su hija. ${ }^{7}$ Esta imagen de Helios sabedor de todas las cosas, también contiene los elementos de su ética y naturaleza profética, que parece haber sido la causa de que Helios sea confundido e identificado con Apolo, aunque eran originalmente muy distintos. ${ }^{8}$ Dicha identificación, de hecho, nunca se llevó a cabo por completo, ya que ningún poeta griego jamás hizo que Apolo montase el carro de Helios a través de los cielos, y entre los romanos nos encontramos con esta idea solo después de la época de Virgilio. ${ }^{9}$ Las representaciones de Apolo con rayos alrededor de la cabeza, que lo caracterizan de manera idéntica al Sol, pertenecen a época romana. Es necesario recordar que Helios y Febo-Apolo no siempre han sido identificados como un único dios.

En nuestro caso, Helios conseguirá sobrevivir básicamente por dos motivos: el primero, por el importante papel que tenía asignado (conducir el carro del Sol) y, el segundo, por la importancia de su culto en el Mediterráneo. ${ }^{10} \mathrm{De}$

6. Ov. Met. II. 106; Hygin. Fab. 183; Schol. ad Eurip. Pholen. 3; Pind. Ol. VII. 71. Se ha relacionado este recorrido de Helios con las posteriores carreras de cuadrigas en el mundo romano. El número de puertas era de doce en el circo romano, igual al número de meses o signos del zodíaco. Una carrera constaba de siete vueltas -igual que los planetas o días de la semana-. Había cuatro equipos, los blancos representaban el invierno, el verano los rojos, verdes la primavera y el otoño los azules (Terc. De. Spect 9.5). Para una discusión completa de este simbolismo, J. Humphrey: Roman Circuses: Arenas for Chariot Racing, University of California Press, 1986.

7. Hom. Od. VIII. 271, Hymn. in Cer. 75; comp. Soph. Ajax, 847.

8. G. Wissowa: Religion und Kultus der Römer, Munich, 1912, p. 365; G. Halsberghe: The Cult of Sol Invictus, EPRO, Leiden, 1972; M. WALLRAFF: «Constantine's Devotion to the Sun after 324», en: M.F. Wiles, E. Yarnold \& P.M. Parvis (ed.), Papers Presented at the Thirteenth Conference of Patristic Studies held in Oxford 1999, Studia Patristica 34, pp. 256-269, rechaza un origen sirio para el culto imperial del Sol, pero mantiene el concepto de dos formas diferentes de culto solar: el republicano, y el tardoimperial. P. Matern: Helios und Sol, pp. 45-56, adopta una posición más matizada, y postula un cierto grado de continuidad entre el Sol republicano y el dios del Sol de la Antigüedad tardía.

9. K. Косн: Gestirnverehrung im Alten Italien: Sol Indiges und der Kreis der Di Indigetes, Fráncfort del Meno, 1933, fue el primero en estudiar la figura del Sol en época republicana de manera sistemática, y argumentó a favor de la aceptación de la antigüedad de su culto; G. DumÉzIL: Archaic Roman Religion, Chicago: University of Chicago Press, 1970, pp. 169-170, se mantuvo escéptico, pero ahora la mayoría de los especialistas acepta esta antigüedad; K. LAттE: Römische Religionsgeschichte, Múnich, 1960, pp. 231233; G. Halsberghe: The Cult of Sol Invictus, pp. 26-28; J.C. Richard: «Le culte de Sol et les Aurelii: À propos de Paul Fest. p. 22 L.», en Mélanges offerts à Jacques Heurgon: L'Italie préromaine et la Rome républicaine (Rome, 1976), París, pp. 917-918 y n. 15, con referencias; R. Schilling: «Le Culte de l'Indiges à Lavinium», $R E L, 57,1979$, pp. 60-61. Para la posible conexión con los Aurelii véase G. DumÉzIL: Archaic Roman Religion, pp. 432-4333; J.C. RiCHARD: op. cit., que aceptan la relación, y C. SANTI: «A Proposito della 'vocazione solare' degli Aurelii», SMSR, 15.1, 1991, pp. 5-19, que sugiere que la supuesta vinculación con los Aurelii es una falsificación que data del reinado de Aureliano. Para la presunta importancia del Sol en época republicana, cf. M. WALlRAfF: «Constantine's Devotion...», pp. 28-29.

10. Helios era una deidad menor para los griegos, pero claramente no era una divinidad extranjera, y su importancia aumentó gradualmente con el tiempo. M. WALlRafF: «Constantine's Devotion...», p. 29, afirma que los cultos de Helios en Grecia eran reminiscencias de cultos arcaicos o no griegos que 
hecho, muchos de sus hijos habitarán zonas muy alejadas unas de otras, desde Creta hasta Italia, siendo algunos de ellos personajes tan importantes como Pasifae (madre del Minotauro), Circe (que aparecerá en la Odisea) o Eetes (rey de la Cólquida). Sin embargo, esta independencia y autonomía del Sol con respecto a Febo se vio truncada -especialmente a partir de época helenística-, ya que las connotaciones solares del dios de Delfos, y su mayor popularidad, facilitaron su identificación. ${ }^{11}$

La presencia geográfica de Helios en el ámbito griego fue bastante variada. Fue el dios tutelar de Rodas, ${ }^{12}$ mientras en la isla de Sicilia, donde tenía rebaños de bueyes y ovejas, cada uno compuesto de 350 cabezas, estos eran atendidos por sus hijas Faetusa y Lampetia. ${ }^{13}$ Las tradiciones posteriores le atribuyen también cierta presencia en Eritea, ${ }^{14}$ y era un denominador común la presencia de rebaños sagrados, especialmente de bueyes. Parece que desde la época homérica fueron construidos templos a Helios en Grecia (Hom. Od. XII. 346), y en una cronología más tardía nos encontramos con su culto establecido en diversos lugares, como en Elis (Paus. VI. 25.5), Apolonia (Herodes IX.93), Hermione (Paus. II. 34.10), en la acrópolis de Corinto (Paus. II 4.7), Argos (Paus. II.18.3), en Trecén (Paus. II. 31.8), Megalópolis (Paus. VIII. 9.2), y otros lugares, especialmente en la isla de Rodas, donde el famoso coloso de Rodas era una representación de Helios. ${ }^{15}$ Los sacrificios ofrecidos a Helios consistieron en carneros blancos, jabalíes, toros, cabras, corderos, especialmente caballos blancos, y miel ${ }^{16}$. Entre los animales sagrados para él, el gallo es mencionado especialmente (Paus. V. 25.5). Los poetas romanos, cuando se habla del dios del Sol, ${ }^{17}$ por lo general adoptan las nociones griegas utilizadas para Helios,

retrocedieron gradualmente en el curso del desarrollo cultural de Grecia. Esta hipótesis no está apoyada por las evidencias de P. Matern: Helios und Sol, n. 3, que implican que los cultos de Helios fueron notablemente más extendidos en el mundo griego en el primer período imperial (s I a.C.- s. I d.C.) de lo que habían estado en la Grecia clásica. El aumento en la cantidad de evidencias puede ser el resultado de otros factores además de un aumento de culto por sí mismo -la supervivencia de inscripciones por ejemplo-, pero eso no cambia el hecho de que el culto de Helios no era poco común en el mundo griego en el comienzo de la era romana.

11. M. Salzman: On Roman Time: The Codex-Calendar of 354 and the Rhythms of Urban Life in Late Antiquity. Berkeley: University of California Press, 1990, pp. 127, 150; Q. SCHOFIELD: «Sol in the Circus Maximus», Latomus, 102, 1969, pp. 640-650. Esto no es un fenómeno aislado. De hecho, y resulta bastante curioso que Artemis, hermana de Apolo, acabará identificándose con la diosa Selene, es decir, con la Luna, que era la hermana de Helios.

12. Pind. Ol. VII. 54; Strab. XIV. p. 652; Plin. HN. XXXIV. 7, 17.

13. Hom. Od. XII. 128; Apollon. Rhod. IV. 965.

14. Apollod. I. 6.1; Theocrit. XXV. 130.

15. Pind. Ol. VII. 54; Strab. XIV. p. 652; Plin. HN. XXXIV. 7, 17. M. NiLsson: Geschichte der griechischen Religion, Múnich, 1941, I, pp. 789-793. En las fuentes M. Nilsson: Geschichte der griechischen, p. 790, n.5, aduce - Ar. Pax 406- 413; Pl. Cra. 397C, ya que indican claramente que en la Atenas clásica los cultos principales de Helios se asociaron con los no griegos en vez de griegos, pero eso no quiere decir que los propios griegos no consideraban Helios y Selene como dioses. Por el contrario, en Pl. Ap. 26d, por ejemplo, se muestra claramente que la actitud normal en Atenas sería la de considerar que el Sol y la Luna eran deidades.

16. Hom. Il. XIX. 197; Eustath. ad Hom. pp. 36, 1668; Hygin. Fab. 223; Paus. III. 20. 5; Herod. I. 216; Strab. XI. 513

17. Etimologías de la palabra Sol están dadas por Var. 1. 5,68; Cic. N.D. 2.68, 3.54; Macr. Sat. 1.17.7, Somn. 1.20.4; Mart. Cap. 2.188; Lyd. Mens. 2.4. 
ya que el culto del Sol se introdujo en Roma después de su familiarización y contactos con culturas orientales, si bien desde un período más temprano es posible identificar ejemplos de cultos al Sol y a la Luna. ${ }^{18}$

\section{ICONOGRAFía DEL PODER y LA LUZ EN LAS Figuras De Helios y SOL}

Las fuentes iconográficas constituyen un rico tesoro de textos potencialmente informativos. Al igual que es difícil captar las sutilezas de un texto escrito si el conocimiento del vocabulario utilizado es inadecuado, es complejo comprender una imagen si la comprensión de uno de los elementos individuales que la definen está ausente. En el caso particular de las figuras de Helios y el Sol en la cultura visual antigua, en numerosas ocasiones los datos iconográficos son escasos, insuficientes y fragmentarios.

En este contexto, ¿cómo podemos identificar iconográficamente las imágenes de Helios y Sol en la cultura visual antigua? Uno de los rasgos más característicos de la iconografía de Helios son los rayos que nacen de su cabeza, siendo normal que aparezca montado en una cuadriga tirada por cuatro caballos, aunque también puede aparecer como un jinete o portando alas. ${ }^{19}$ La pervivencia iconográfica de Helios y su posterior asociación visual con la figura del Sol se produjeron en la cultura visual romana gracias a su vinculación con Febo-Apolo, debido a que de esta forma su riqueza simbólica aumentó de manera considerable (por ejemplo, incorporó algún rasgo propio de Apolo, como es la corona de laurel). ${ }^{20}$ Un fresco en Pompeya (IX 7,19) ${ }^{21}$ es un buen ejemplo de cómo se identificaron el Sol y Apolo en el siglo i d.C. (fig. 1). La figura del Sol está representada irradiando rayos, junto a otros atributos iconográficos como el látigo y la clámide, que identifican claramente a esta figura con nuestra deidad solar.

A modo de resumen, podemos decir que en la cultura visual romana, la iconografía del dios Sol estaba dominada por tres imágenes-tipo básicas. ${ }^{22}$

18. Varro, de Ling. Lat. V. 74; Dionys. II. 50; Sext. Ruf. Reg. Urb. IV. Según Varrón (L. 5,74) el culto debe remontarse a la época de Tito Tacio. En cuanto al origen en época sabina cf. Dion. Hal. Ant. 2.50, 3; Aug. C.D. 4.23. Festo une la introducción del culto a la Aurelii, una familia de origen según se dice sabina (Paul. Fest. 22.5). Esto sugiere que puede haber sido uno de los sacra gentilicia. Tácito (Ann. 15.74.1) menciona una vetus circum apud aedes para el Sol, generalmente aceptada en época republicana en su cronología; cf. Terc. Spect. 8.1.

19. Sobre la iconografía de Helios en el arte griego P. MAtern: Helios und Sol, pp. 47-52, pp. 58-62, pp. 83-87, pp. 166-169. Sobre la iconografía del Sol el trabajo más completo es el de S. HiJmans: Sol: The sun in the art and religions of Rome [S.1.], 1994.

20. También se han identificado coronas de laurel simbólicas asociadas a los rayos solares, cf. P. BASTIEN: Le buste monétaire des empereurs romains, Wetteren, 1992, pp. 117-118.

21. LIMC Helios/Sol 302.

22. En las convenciones iconográficas, LIMC Helios/Sol. R. BERNHARD: «Der Sonnengott auf griechischen und römischen Münzen», Schweizerische Numismatische Rundschau, 25, 1933, pp. 245-298; K. Schauenburg: Helios; Archdologisch-mythologische Studien iiber den antiken Sonnengott, Berlín, 1955; P. MATERn: Helios und Sol, p. 47. Algunas fuentes antiguas proporcionan información pertinente sobre la iconografía, por ejemplo Tert. De Spect. 9.3; Verg. Aen. 12, 164. 
1. Como una figura de pie, siempre joven e imberbe, con el cabello largo y suelto. Suele irradiar rayos de la cabeza. Casi invariablemente, viste una clámide -a veces larga, aunque generalmente corta-, y aparece desnudo, a menos que vista una larga túnica. Su principal atributo es el látigo, pero el globo celeste también es un motivo recurrente. Otros atributos menos frecuentes son un cetro, una lanza, y una antorcha. Desde el siglo I d.C. en adelante, puede ser representado con la mano derecha levantada y extendida. Este gesto se volvió cada vez más popular en el siglo II d.C., y en los siglos III y IV. La postura más común es en contrapposto, aunque en las monedas aparece también caminando o corriendo. En términos generales, resulta extraño encontrar representaciones del Sol realizando una actividad específica.

2. Como un auriga en un carro, con las mismas convenciones iconográficas que las anteriormente descritas. En este caso concreto, el Sol conduce una cuadriga, y normalmente de pie sobre ella. En algunas representaciones tridimensionales la cuadriga se representa de perfil, aunque las imágenes en tres cuartos y frontales también son frecuentes. ${ }^{23}$ Los caballos pueden representarse de manera frontal, pero lo más común es que aparezcan en parejas simétricas, enmarcando así la imagen central del Sol.

3. Como un busto o una figura representada parcialmente. Un gran número de representaciones del Sol se limitan a presentar su cabeza o busto, y más raramente la parte superior del cuerpo. En este último caso, la gama completa de la definición de los atributos incluye el látigo, el globo celeste, la mano derecha levantada, la clámide, y los rayos irradiando de su cabeza. Tenemos ejemplos de bustos sin rayos que se encontraron en mitreos, y casi con seguridad representan al Sol. ${ }^{24}$ Muchos bustos y cabezas del Sol tienen una característica iconográfica adicional -un látigo detrás del hombro, por ejemplo- para confirmar aún más su identidad.

De esta manera, la cultura visual romana representó al Sol, invariablemente, como un hombre joven, bien afeitado, casi siempre irradiando rayos alrededor de su cabeza, y habitualmente con un látigo y/o un globo celeste. Aparece en general desnudo, a pesar de que puede llevar un manto o clámide

23. P. Matern: Helios und Sol, pp. 124-127, subestima el número de numismática, y otras representaciones del Sol con una mano levantada en una cuadriga. En monedas que representan la cuadriga de perfil (derecha o izquierda) del Sol, por ejemplo, se afirma incorrectamente que se le representa con una mano derecha levantada solo en raras ocasiones, y solo desde el reinado de Probo (276-282). De hecho, algunas monedas con esta iconografía se ha encontrado en relación con Caracalla en los años 215, 216, 217 así como una bajo Póstumo, posiblemente dos bajo Galieno, y una bajo Aureliano, R. GöBl: Antike Numismatik, Múnich, 1978, p. 149. Floriano (276) también acuñó una serie de monedas de este tipo en su corto reinado.

24. M. Bergmann: Die Strahlen der Herrscher: Theomorphes Herrscherbild und politische Symbolik im Hellenismus und in der römischen Kaiserzeit, Maguncia, 1998, pp. 76-77, pl. 14,1-3, considera que la posibilidad de que esta estatua sea Alejandro es bastante alta. P. MAtern: Helios und Sol, pp. 120-122, sostiene que es Helios. 


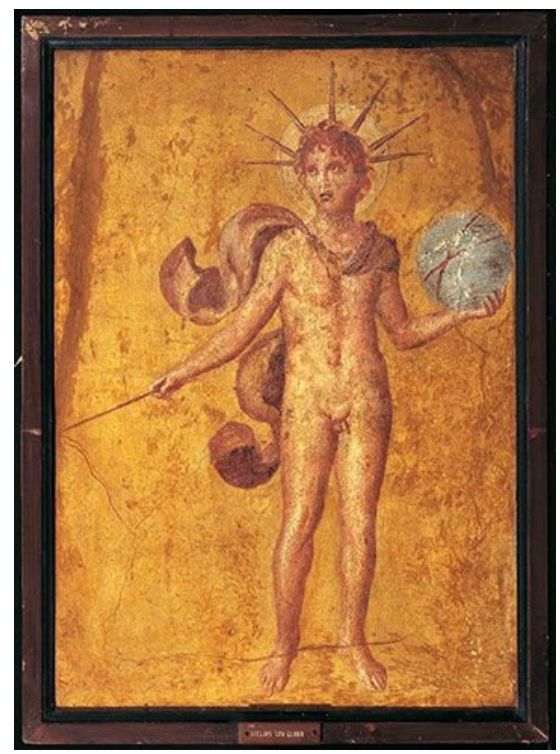

Fig. 1. Figura de Sol-Apolo en una pintura de Pompeya IX 7,19. LIMC LIMC Helios/Sol 302

que cubre su anatomía parcialmente. En el conjunto general de la cultura visual romana son escasísimos los ejemplos que han sobrevivido y que puedan ser identificados de manera inequívoca con el Sol. Papini señala que no hay figuras desnudas que no sean el Sol, siendo el látigo un atributo estándar en el arte romano. ${ }^{25} \mathrm{~A}$ partir de estas pocas premisas iconográficas, podemos identificar algunas figuras como el Sol. Una escultura en Copenhague es uno de los ejemplos que ha sido más ampliamente aceptada como representación del Sol, y probablemente esta identificación sea correcta (fig. 2) ${ }^{26}$ En ella encontramos la figura del Sol de pie, desnudo pero con clámide, el pelo largo y rizado, y un nimbo que irradia rayos esculpidos en relieve. ${ }^{27}$ Mientras que el brazo derecho aparece levantado (roto por encima del codo), el brazo izquierdo sostuvo un atributo hoy perdido; un caballo aparece como soporte. La reconstrucción de esta estatua es dudosa.

En cronología imperial temprana, las representaciones del Sol pueden aparecer levantando su mano derecha, imitando un gesto de detención. Apenas

25. M. PAPINI: «Una statua di Sol a Palazzo Barberini», RömMitt, 109, 2002, p. 96

26. LIMC Helios/Sol 460, 461.

27. P. MAtern: Helios und Sol, pp. 176-181, distingue varias categorías de rayos en las esculturas de piedra. Lo más reseñable de este tipo de ornatos es su aspecto tridimensional del halo con rayos en relieve. Esto permitió que el artista optara por los rayos de piedra en lugar de clavos de metal sin el riesgo de que los rayos se romperían fácilmente. 


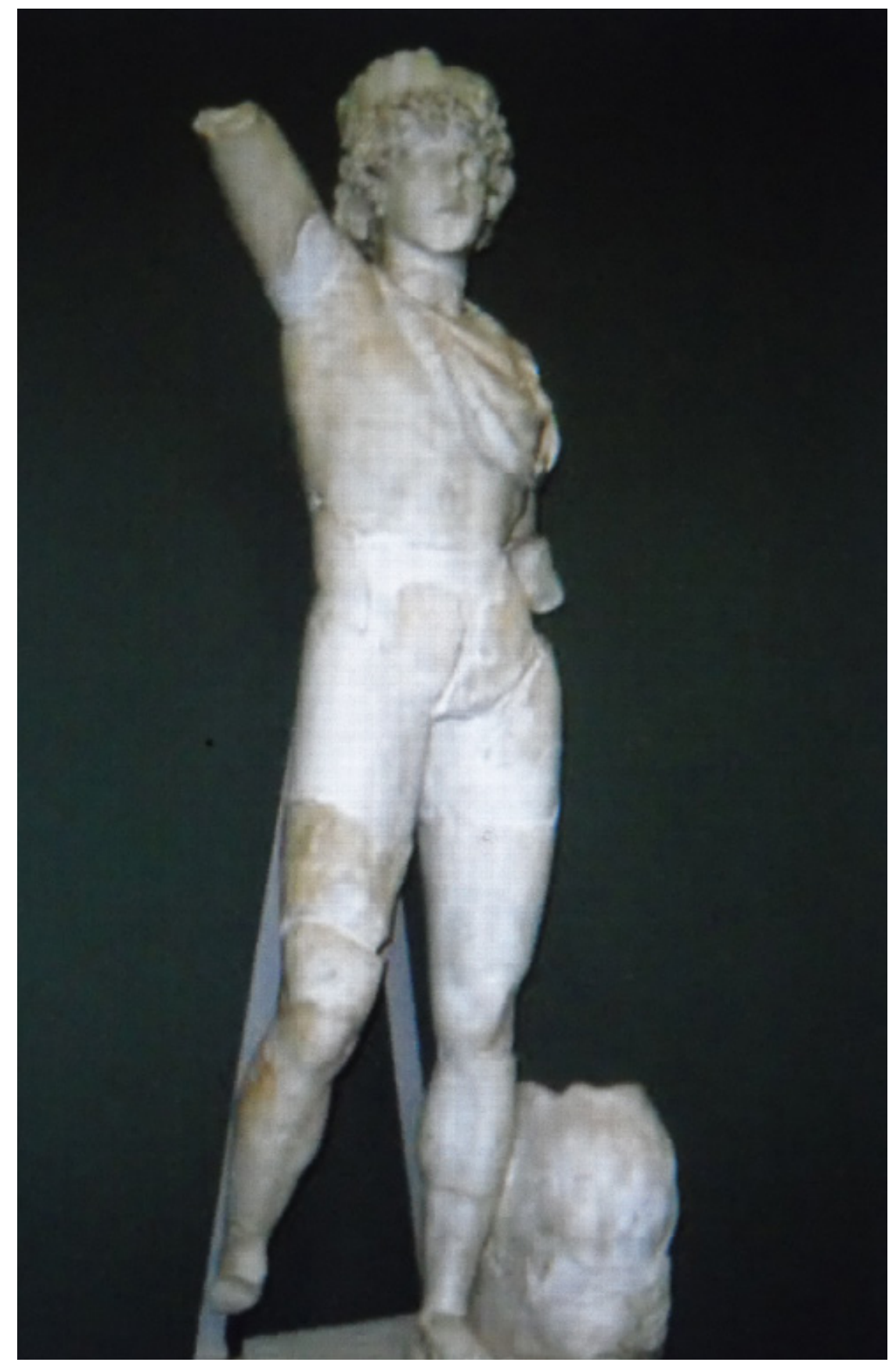

Fig. 2. Escultura romana del Sol, tercer cuarto del siglo Iv. Gliptoteca de Copenhague, 623. LIMC Helios/Sol 460, 461 
existen variaciones locales, y en todas las partes del Imperio se produjeron numerosas representaciones del Sol que se adhieren a esta iconografía estándar en la mayoría de aspectos. ${ }^{28}$ Por tanto, cuando se produjeron variaciones, mejor es asumir que estas fueron realizadas conscientemente para diferenciar la figura representada de las imágenes canónicas del Sol. Otras excepciones incluyen las más raras representaciones del Sol como participante activo en las escenas mitológicas y de Mitra, y un muy pequeño número de gemas posiblemente representan al Sol a caballo o montando un león. ${ }^{29}$

La iconografía de estos tipos de imágenes del Sol está estrechamente relacionada con la iconografía clásica y helenística de Helios, y las diferencias que existen tienden a ser asuntos de énfasis, y no de fondo. En el arte griego, Helios aparece generalmente vestido con una túnica de algún tipo, mientras que en el arte romano el Sol tiende a ser representado desnudo. En ambas culturas visuales, uno de los atributos que está presente desde una cronología más temprana es el látigo. El cambio más notable en la iconografía del Sol se produjo en el curso del siglo iI d.C., cuando se hizo cada vez más común que fuera representado con la mano derecha levantada. En otros aspectos, sin embargo, la iconografía del Sol se mantuvo constante durante medio milenio o más. ${ }^{30}$ El rasgo iconográfico más identificativo del Sol es su carácter imberbe,

28. En Siria, por ejemplo, dioses más juveniles se representan irradiando rayos, están armados y llevan una armadura de cuerpo completo, pero no representan al Sol, sino una deidad local como Malachbel, cf. H. Seyrig: «Antiquités Syriennes 95. Le culte du Soleil en Syrie à l'époque romaine», Syria, 48, 1971, pp. 337-373. La mayoría de los estudios más recientes sobre la divinidad del Sol han abandonado la idea de una deidad sirio importada. S. Hijmans: «The Sun which did not Rise in the East: the Cult of Sol Invictus in the Light of non-literary evidence», BABesch, 71, 1996, pp. 115-150.; M. WALLRAFF: «Christus Verus Sol: Sonnenverehrung und Christentum in der Spätantike», Jahrbuch für Antike und Christentum, Erg. Bd. 32, Aschendorff, Münster., pp. 12-13; p. MATERn: Helios und Sol, pp. 35-39. Sobre el papel de deidades solares en Siria, cf. P. MAtern: Helios und Sol, pp. 36-37, pp. 134-137. Para los últimos resúmenes de culto del Sol imperial ampliamente a lo largo de las líneas tradicionales véase R. MACMuLLEN: Paganism in the Roman Empire, Londres, pp. 85-86; G. HALSBerghe: The Cult of Sol Invictus, EPRO 23, Leiden; W. Kellner: «SolMünzen als Zeugnisse einer politischen Religion», en: Festschrift Herbert A. Cahn, Basilea, 1985, pp. 59-77, 60-1, 64; R. Muth: Einführung in die griechische und römische Religion, Darmstadt., 1988, p. 190, n. 519; M. Clauss: «Sol Invictus Mithras», Athenaeum, 78, 1990, pp. 423-450; S. Di PalmA: «Evoluzione dei culti solari a Roma. Il Sol Invictus da Settimio ad Alessandro Severo», en: Gli imperatori Severi. Storia, archeologia, Roma, 1999, pp. 333-336; P. GARCía AguAdo: «El culto al Sol Invictus en la ipoca de Caracalla», Hispania Antiqua, 25, 2001, pp. 295-304; R. Hansen: "Antike Sonnenkulte", Acta Historica Astronomiae, 25, 2005, pp. 66-91.

29. En ciertos contextos - principalmente de Mitra- el Sol también podría representarse con más libertad que las líneas estrictas del esquema dominante. Tampoco hay que olvidar las representaciones no icónicas del Sol. En la arquitectura, el Sol podría integrarse en el diseño iconográfico y arquitectónico a través de un manejo cuidadoso de la admisión de la luz solar, cuyo mejor ejemplo es el Serapeum en Alejandría, donde los rayos de luz que entran a través de un pequeño agujero descubierto en el momento justo caerían precisamente en los labios de la estatua de culto, que representa al Sol besando a Sarapis, cf. V. TRAN TAM TinH: «Le baiser d'Hélios», en: Alessandria e il mondo ellenistico-romano. Studi in onore di Achille Adriani, Roma, II, 1984, pp. 318-328. Sobre el uso de la luz en la arquitectura sagrada, cf. C. Williamson: «Light in Dark Places: Changes in the Application of Natural Light in Sacred Greek Architecture», Pharos, 1, 1993, pp. 3-33.; E. PARISINOU: The Lighht of the Gods: the Role of Light in Archaic and Classical Greek Cults, Londres, 2000.

30. K. Dunbabin: «The Victorious Charioteer on Mosaics and Related Mouments», AJA, 86, 1982, pp. 65-89. 


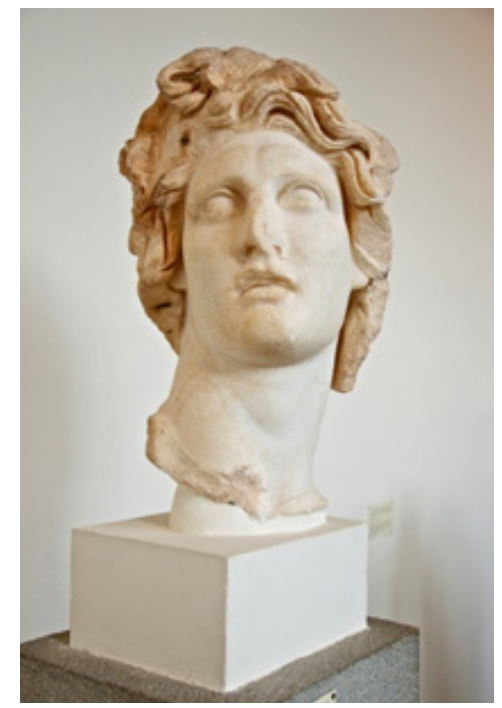

Fig. 3. Busto de Alejandro-Helios, segunda mitad del siglo II a.C. Museo Arqueológico de Rodas, E 49

ya que una figura barbada no puede ser el Sol. ${ }^{31}$ Su cabello habitualmente toma la forma de gruesos mechones sueltos. Su estética capilar se combina con una cabeza ligeramente inclinada, cejas fuertes, boca ligeramente abierta, y tal vez una mirada hacia arriba: las similitudes con los retratos de Alejandro Magno no pueden ser ignoradas.

Un problema similar de interpretación ha surgido con respecto a las características juveniles del Sol, que pueden ser confundidas con elementos de retratos de Alejandro Magno, hasta tal grado que muchos especialistas han sugerido que en algunos casos el representado no es el Sol, sino Alejandro bajo la apariencia de Helios. ${ }^{32}$ Numerosas imágenes han sido interpretadas como representaciones de Helios o el Sol, y como Alejandro-Helios o incluso como Alejandro, y en pocos ejemplos se ha podido llegar a un acuerdo común (fig. 3). ${ }^{33}$

31. Esto es cierto desde el arte clásico griego en adelante. En el arte griego arcaico, el Sol se representa a veces con barba, P. Matern: Helios und Sol, p. 47.

32. Los enfoques van desdeM. BIEBER: Alexander the Great in Greek and Roman Art, Chicago, 1964, que hace caso omiso de la relación Alejandro-Helios, salvo una breve observación en la p. 71. A. NiELSEN: «The Mirage of Alexander -a Minimalist View», AnalRom Suppl, 20, 1993, pp. 137-144, expresa se tiene la sensación desagradable de que los criterios para la identificación varían según el gusto individual.

33. N. Hannestad: «Imitatio Alexandri in Roman Art», AnalRom Suppl. 20, 1993, pp. 61-69; A. NielSEN: «The Mirage of Alexander...», p. 140. En general sobre los enfoques de los retratos de Alejandro es imprescindible el excelente resumen dado por A. STEwart: Faces of Power. Alexander's Image and Hellenistic Politics, Berkeley, 1993, pp. 56-70. 
Los elementos iconográficos mencionados no prestan motivos suficientes para identificar estos bustos como esculturas del Sol. ${ }^{34}$ En algunos casos ha sido el contexto de las imágenes el encargado de aclarar la identificación, ya que se encontraron algunos bustos en los santuarios de Mitra. ${ }^{35}$ La presencia del Sol es obligatoria en los templos de Mitra, mientras que la presencia de Alejandro sería una anomalía, por lo que es una conclusión inevitable que estos bustos representan al Sol, y así eran vistos como tales. Desde esta perspectiva, los rasgos de las imágenes de Alejandro identificados con las del Sol son simplemente un ejemplo de cómo los artistas romanos desplegaron elementos del rico vocabulario visual de Roma para definir al Sol, ${ }^{36}$ ya que era en el panteón romano la divinidad por excelencia de la juventud ardiente e invencibilidad (Sol Invictus).$^{37}$ Bergmann ha revisado una serie de imágenes de figuras que aparecen irradiando rayos que pueden o no ser Alejandro. ${ }^{38}$ Su revisión muestra lo difícil que es encontrar un criterio por el cual estas imágenes se pueden identificar con seguridad como Alejandro, el Sol o alguna otra deidad. De hecho, lo que emerge con más claridad es que no se puede discriminar con éxito entre el Sol y Alejandro, a menos que existan elementos iconográficos específicos que nos hagan desechar algunas de las dos opciones.

34. Las evidencias para la identificación entre Alejandro-Helios es deducida por A. STEWART: op. cit., p. 334. Aunque Diodoro (17.89.3) y Curtius (9.1.1) afirman que Alejandro ofreció sacrificios a Helios en agradecimiento por haber permitido la conquista de Oriente, esto difícilmente constituye una prueba de que Alejandro se reivindica ningún vínculo especial con Helios (Arriano, V. 10, que establece simplemente que Alejandro ofreció a los dioses, sin mención especial de Helios).

35. Hay que recordar que el busto no tiene por qué haber tenido rayos de metal de algún tipo, ya que podría haber sido colocado en frente de alguna fuente oculta de luz que se proyectaba desde atrás o por encima, por ejemplo. En el amplio uso de efectos de luz especiales en los santuarios de Mitra véase $M$. CLAuss: The Roman Cult of Mithras: the God and his Mysteries, Londres, pp. 127-130.

36. D. Spencer: The Roman Alexander: Reading a Cultural Myth, Exeter, 2002, su fascinante estudio se centra en la recepción e interpretación del Alejandro histórico por la élite romana de la República y principios del Principado, como lo demuestran sus escritos. Véase también P. STEWART Roman Art, Oxford, 2004.

37. En la utilización de época republicana de invictus como epíteto divino, cf. S. WEINSTOCK: «Victor and Invictus», HarvTheolR, 50, 1957, 215-217. F. Cumont: Textes et Monuments Figurés relatifs aux Mystères de Mithra, vol. 1, 1899, pp. 47-48, n. 2, en referencia a las muchas inscripciones en CIL VI (n. ${ }^{\circ}$ 312-332), está desconcertado por la popularidad de Hercules Invictus. Él sugiere que en estos casos Hercules significa el planeta Marte. Con Júpiter el epíteto Invictus es simplemente poético como omnipotens. De hecho Cicerón (leg. 2, 28) indica claramente que Invictus era un epíteto normal para Júpiter. S. BERRENS: Sonnenkult und Kaisertum von den Severern bis zu Constantin I. (193-337 n. Chr.), Stuttgart, 2004, pp. 184198, diferencia entre el uso mitraico de Sol Invictus Mitra y la aparición de Sol Invictus en las monedas, inscripciones imperiales, y otros monumentos públicos.

38. A. NielsEN: "The Mirage of Alexander...», p. 141, sugiere que los espectadores contemporáneos posiblemente hayan tendido a vacilar entre algunas imágenes que podrían identificarse con Alejandro, Aquiles, Perseo, Apolo, etc. El hecho es que supuestamente los rasgos de Alejandro eran, de hecho, las herramientas artísticas convencionales que no se refieren a un individuo particular -Alejandro- sino a una concepción heroica del individuo. T. VAsilieva: «Alexander as Helios or Helios as Alexander: Some problems of interpretation and attribution of an unknown monument» VDI, 251:4, 2004, pp. 136-153, apunta la imagen fuertemente idealizada de Alejandro (especialmente en los retratos póstumos) se hizo tan conocida que formó parte de la iconografía griega en la época helenística y romana, y acabó absorbiendo toda una serie de otras imágenes, divinas y mitológicas. 


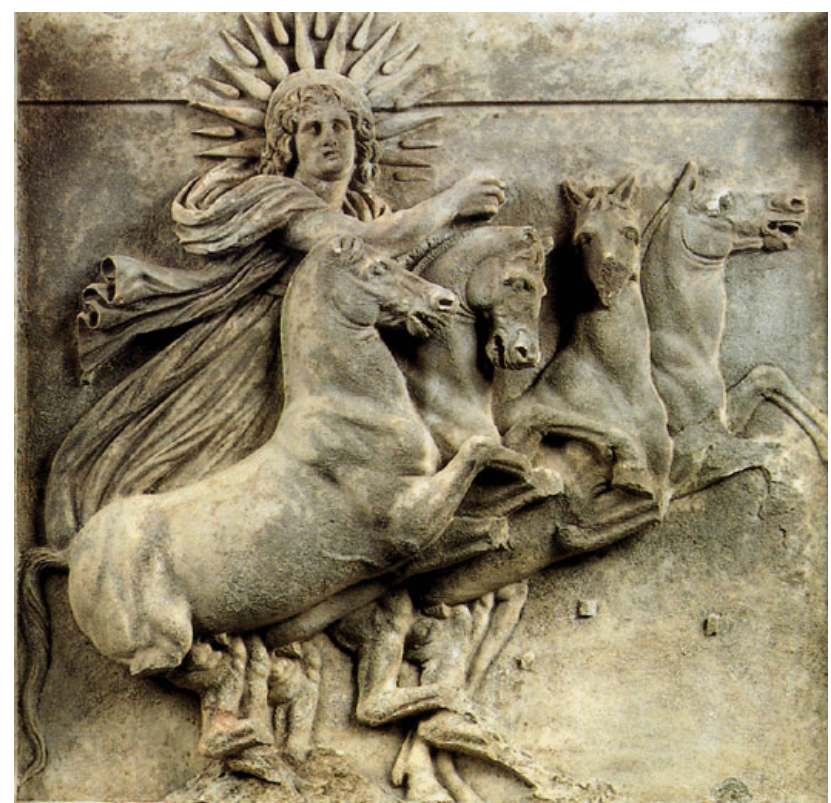

Fig. 4. Relieve de Helios. Frontón noroeste del templo de Atenea en Ilión, primer cuarto del siglo III a.C. Museo de Pérgamo (Berlín)

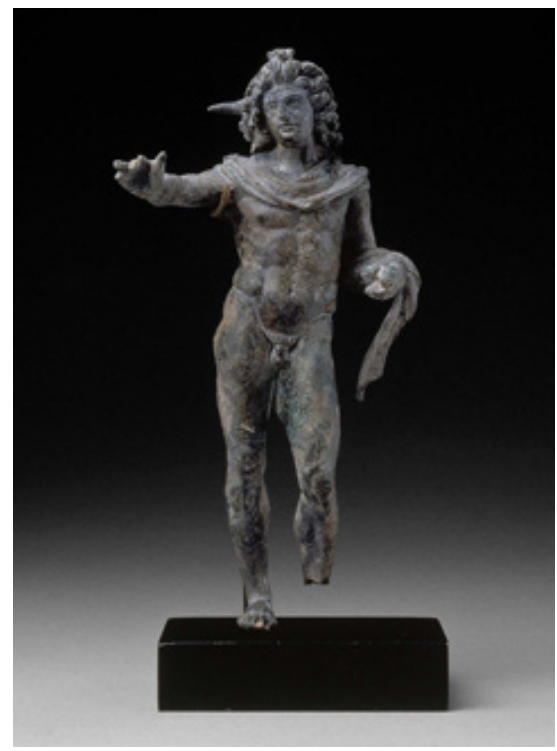

Fig. 5. Bronce romano con la figura del Sol, período Antonino (inicios siglo II). Museum of Fine Arts (Boston), 1996.3 
Los rayos o un nimbo irradian luz desde su cabeza, y forman tal vez el elemento más importante de su iconografía. ${ }^{39}$ Los rayos son generalmente descritos emanando directamente de la cabeza del Sol, pero en casos excepcionales pueden ser representados como si estuvieran conectados a un añadido metálico que rodea la cabeza en forma de corona. ${ }^{40}$ En muy pocos casos, el Sol puede ser representado en una cuadriga que está irradiando luz pero, por lo demás, nunca es representado con los rayos procedentes de cualquier parte de su cuerpo excepto de la cabeza (fig. 4). En particular, durante los siglos III y IV d.C., uno de los elementos más llamativos de la iconografía del Sol lo encontramos en la manera en que levanta el brazo derecho. En ese período -casi invariablemente- es representado con este gesto cada vez que aparece como una figura de cuerpo entero. Por lo general, el brazo está extendido, aunque su codo aparece ligeramente flexionado, y la mano abierta está a la misma altura que la cabeza. La postura en general es bastante relajada, en relación con el gesto propio de un orador en su adlocutio, como un gesto de poder, bendición, o saludo, como la del emperador en muchas estatuas ecuestres (fig. 5). El Sol ciertamente nunca adopta la postura rígida del saludo fascista, ni es una postura amenazante o apotropaica.

Un último elemento iconográfico presente en la cultura visual romana de manera recurrente es un globo celeste que representa al cosmos. Tanto en forma y función, la aparición de este globo acompañando al Sol es un dato iconográfico de enorme utilidad. El globo representa el cosmos, y cualquier figura que llevaba este símbolo estaba representada como un motor primario del orden universal. ${ }^{41}$ Hacia el final de la República romana, el globo celeste se había convertido en un símbolo abstracto de la energía (cósmica), con ejemplos como Júpiter, Dea Roma, o el Genio Populi Romani representados regularmente sosteniendo un globo celeste. De César en adelante, todos los gobernantes romanos llevaron el globo como un signo de su poder. Se ha convertido claramente un signo convencional del poder supremo, aunque eso no quiere decir que su simbolismo cósmico haya sido olvidado.

39. M. WallRAFF: «Christus Verus Sol: Sonnenverehrung und Christentum in der Spätantike», Jahrbuch für Antike und Christentum, Erg. Bd. 32, Aschendorff, Münster, 2001, p. 147, hace hincapié en que hay ejemplos de retratos nimbados dispersos durante la Tetrarquía.

40. La diferencia entre una aureola con rayos y una sin ellos a menudo se pasa por alto, lo que lleva a muchos a tomar el punto de vista equivocado de que la aureola era un símbolo astral o incluso principalmente un símbolo solar, M. WALlrafF: «Christus Verus Sol...», p. 129.

41. El globo cósmico no debe ser confundido con el globo terrestre. En la Antigüedad, la idea de que la tierra era redonda fue controvertida, pero no hay acuerdo sobre cómo era de generalizada la oposición al concepto que estaba en los círculos de la sociedad antigua responsables del desarrollo de las convenciones iconográficas. Para contrastar puntos de vista, P. Arnaud: «L'image du globe dans le monde romain. Science, iconographie, symbolique», MEFRA, 96, 1984, pp. 53-116. 


\section{UN RASGO ICONOGRÁFICO PARTICULAR: LA CORONA RADIATA}

A pesar de toda esta serie de motivos iconográficos distintivos, ninguno de ellos en particular es suficiente para identificar a una figura de manera absoluta con el Sol. En lo que se refiere a nuestro estudio iconográfico sobre la corona radiata ${ }^{42}$ la radiación es uno de los elementos simbólicos que no son definitorios de nuestra figura. Además, ciertos tipos de radiación no se asociaban directamente con el Sol. ${ }^{43}$ Todavía hay una fuerte tendencia a asumir que la luz simbólica de cualquier tipo puede ser suficiente para asociar una figura con el Sol, con independencia de las otras características iconográficas de la figura radiante. ${ }^{44}$ Es cierto que hay casos en los que la identidad principal de una figura como un personaje que no sea el Sol es inequívoca y, sin embargo, al mismo tiempo, su iconografía puede contener referencias claras al Sol. ${ }^{45}$ Del mismo modo, existen ejemplos en los que se excluyen cuidadosamente las referencias al Sol para evitar que los espectadores asuman connotaciones solares.

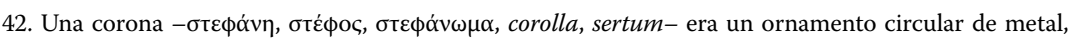
hojas o flores, usado alrededor de la cabeza o el cuello, y utilizado como decoración festiva y funeraria, y como recompensa de talento, de destreza militar o naval, o del valor civil. La corona radiata fue la que se entregaba a los dioses y héroes deificados (Stat. Theb. I.28), y fue asumida por algunos de los emperadores, como muestra de su divinidad. Era de uso emblemático y no honorario, por lo menos a la persona que las usaba, y su adopción no estaba regulada por la ley, sino por la costumbre. Se puede ver este atributo iconográfico en las monedas de Trajano, Calígula, M. Aurelio, Valerio Probo, Teodosio, etc. Los tipos de coronas honorarias comunes en la cultura visual romana fueron: corona obsidionalis (corona honoraria otorgada por los romanos para los logros militares. (Aul. Gell. V.6; Plin. HN. XXII.4; Festus, Obsidionalis; Serv. ad Virg. Aen. VIII.128), corona civica (la segundo en honor e importancia, se entregaba al soldado que había conservado la vida de un soldado romano en batalla, y por lo tanto iba acompañada de la inscripción Ob civem servatum. Plin. HN. XVI.3; Aul Gell. V.6; Senc Clem. I.26), corona navalis o rostrata (seguramente fuera aquella dada al marinero que abordaba por primera vez un barco enemigo. Liv. Epit. 129; Dion Cass. XLIX.14; Aul. Gell. V.6; Senec. De Ben. III.32; Festus, Navalis Corona; Plin. HN. VIII.31), corona muralis (el primer hombre que escalaba el muro de una ciudad asediada era recompensado por su comandante con una corona muralis. Aul Gell, V.6.4, Liv. XXVI.4), corona castrensis o vallaris (el primer soldado que superba el vallum y forzaba una entrada en el campamento del enemigo. Aul Gell, V.6; Val. Max. I.8), corona triumphalis (se usaba alrededor de la cabeza del comandante durante su triunfo, se hacía con hojas de laurel. Aul. Gell, V.6, Ovid., Pont. II.2, 81, Tibull, I.7.7), corona ovalis (se daba a aquellos que meramente merecían una ovación, lo cual ocurrió cuando la guerra no fue debidamente declarada, o fue llevada a cabo contra una fuerza muy inferior, o con personas no consideradas por las leyes de las naciones como enemigos legítimos, como esclavos o piratas. Plut. Marcell. 22; Plin. HN. XV.39; Dionys. V.47), corona oleagina (era una corona de honor, hecha de hoja de olivo, y conferida tanto a los soldados como a sus comandantes. Dion Cass. XLIX.14, XLVI.40). Los tipos de coronas emblemáticas más comunes en la cultura visual romana fueron: corona sacerdotalis (fue usada por los sacerdotes, con la excepción del pontifex Maximus y sus ministros, al oficiar en el sacrificio. Stat. Theb. III.466; Hor. Carm. Sec. 30; Tibull. II.1.4, I.1.5; Tertull. De Idol. 18), corona funebris (se colocaron guirnaldas de flores en el féretro o se dispersaron desde las ventanas bajo las cuales pasaba la procesión fúnebre, o se entrelazaron alrededor de la urna cineraria. Plut. Marcell, 30; Demetr. 53; Ovid. Trist. III.2.82; Tibull. II.4.48), corona convivialis (debe su origen a la práctica de atar una cinta de lana apretada alrededor de la cabeza, con el propósito de mitigar los efectos de una posible intoxicación. Plin. HN. XXI.6; Hor. Sat. II.3.256; Val. Max. VI.9), corona nuptialis (estaba hecha de verbena, recogida por la novia, y llevada bajo el flammeum con el que la novia siempre estaba envuelta. Cat. LXI.6.8; Cic. De Orat. III.58), corona natalitia (suspendida sobre la puerta del vestíbulo en las casas de Roma en el que nacía un niño. Juv. Sat. IX, 85; Meursius, Attic. Lect. IV.10).

43. M. Bergmann: Die Strahlen der Herrscher, pp. 41-46, el resplandor simbólico no le confiere automáticamente a una figura características astrales o solares.

44. M. Bergmann: Die Strahlen der Herrscher, pp. 45-46; P. Matern: Helios und Sol, pp. 181-182.

45. M. Bergmann: Die Strahlen der Herrscher, p. 45; M. Wallraff: «Christus Verus Sol...», pp. 145151; P. Matern: Helios und Sol, p. 181. 


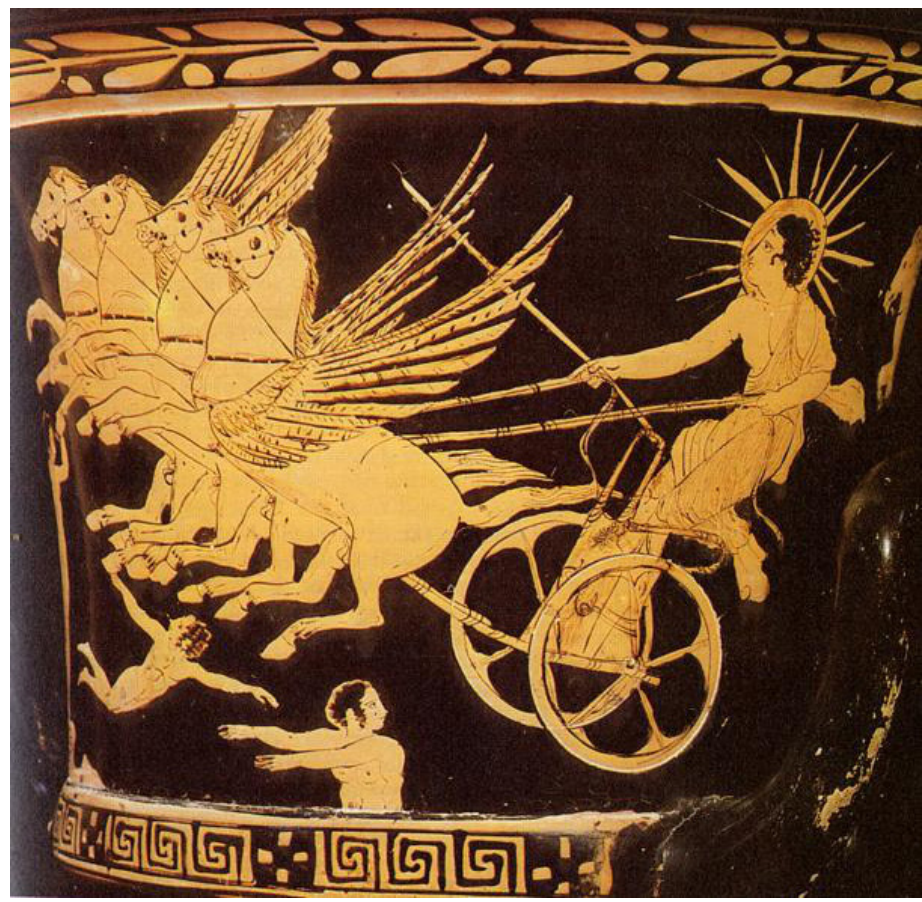

Fig. 6. Crátera de figuras rojas con Helios en su carro, siglo v a.C. Bristish Museum (Londres), inv. GR 1867,0508.1133

La corona radiata es un atributo genérico, presente en la iconografía de Helios desde mediados del siglo v a.C. ${ }^{46}$ Sus posibles raíces orientales están fundamentadas dadas las numerosas representaciones de Helios que aparecen en las monedas de Rodas con la presencia del carro del Sol (fig. 6). Podría plantearse la cuestión de si la imagen, establecida durante tanto tiempo en el mundo griego, podía evocar cualquier asociación visual con Oriente, incluso en el contexto del culto de Alejandro Magno a Helios como el dios que abre el camino hacia el Este. ${ }^{47}$

Dejando a un lado los problemas iconográficos involucrados en el supuesto de que un objeto representado sea parcialmente real (corona) y/o parcialmente no (rayos), podríamos pensar que una corona -símbolo helenístico de la realeza por excelencia- no era el tipo de honor que se podría otorgar a los primeros

46. B. Holden: The Metopes of the Temple of Athena at Ilion, Northampton MA, 1964, p. 36.

47. W. Fauth: Helios Megistos. Zur synkretischen Theologie der Spätantike, Leiden, 1995, p. 38; P. Goukowsкy: Essai sur les origines du mythe d'Alexandre (336-270 av. J.-C.), II: Alexandre et Dionysos, Nancy, 1981, p. 40. 


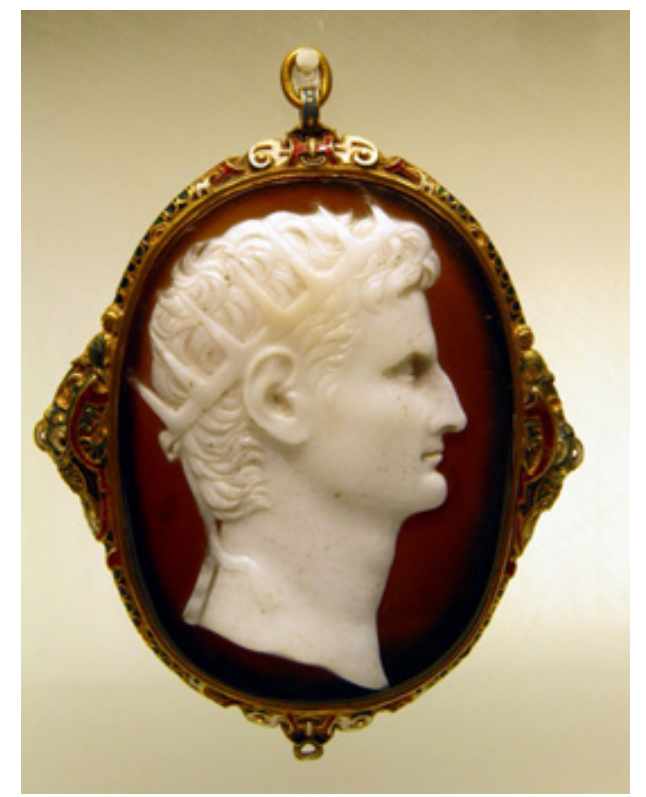

Fig. 7. Camafeo de Augusto con la corona radiata, siglo I. Museo Romisch-Germanisches (Colonia), 8115666537

emperadores de Roma, y ciertamente no en el caso de Augusto. ${ }^{48}$ El hecho de que en Roma fuese precisamente Augusto el primer retratado con este símbolo es mucho más fácilmente comprensible si aceptamos -como Bergmann-que la corona radiata era representada como un tipo de ofrenda floral romana (signo de honor y auctoritas), y no como una corona helenística con los rayos simbólicos (signo de realeza y divinidad) (fig. 7). La corona radiata se otorgaba a los emperadores muertos después de la consecratio (conversión en dioses) y la corona laureada a los generales victoriosos, con imperium. Esta suposición de que la corona radiata de Augusto fue inspirada por los modelos helenísticos es generalizada, pero problemática. La adopción directa de las insignias de los reyes helenísticos -incluso póstumamente- va en contra de la política general de Augusto, y por tanto sería sorprendente. La apariencia física de la corona radiata era más una reminiscencia de coronas honoríficas romanas que de los distintos tipos de coronas y diademas de época helenística. Tan solo

48. Conectado con él había un publicum sacrificium para el Sol el 8 de agosto, y/o feriae el 9 de agosto, dedicado específicamente al Sol Indiges, que también tuvo un templo en Lavinium (Dion. Hal. Ant. 1, 55, 2; Plin., Nat. 3.56). Existía un festival que se celebraba el 28 de agosto en honor del Sol y la Luna, recordado en el calendario del 354, que probablemente también tenía raíces republicanas, si es de hecho la misma que la que se hace referencia en la Fast Praen. (InscrIt 13.2, 134.) 

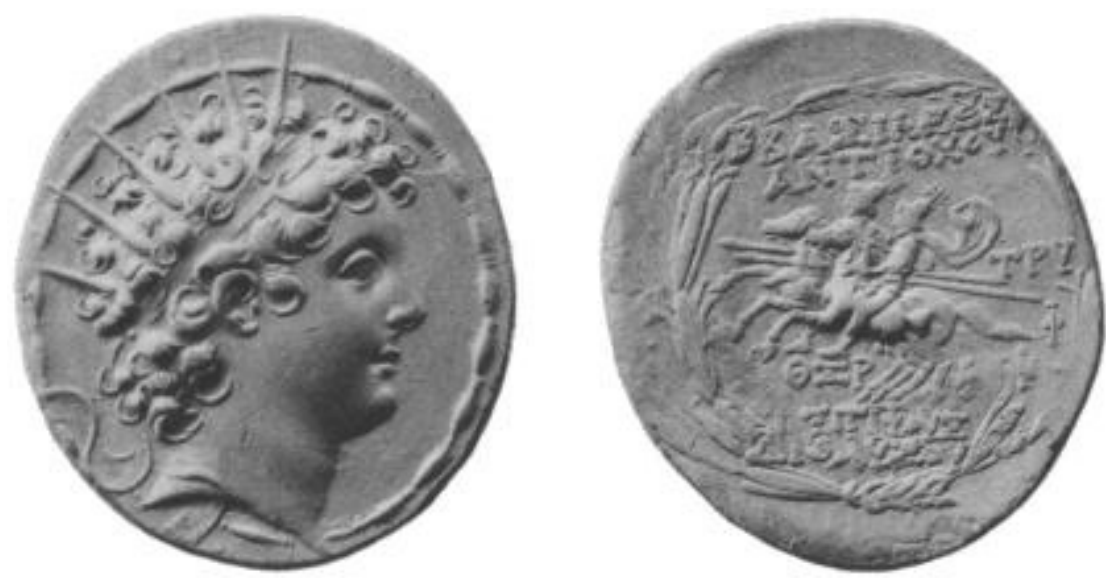

Fig. 8. Moneda de Antíoco VI. El reverso muestra a Castor y Pólux a caballo. En la inscripción griega se lee $\mathrm{BA} \Sigma \mathrm{I} \Lambda \mathrm{E} \Omega \Sigma$ ANTIOXOY (rey Antíoco). La fecha es 169 de la era seléucida, correspondiente al 144-143 a.C

tenemos datos concluyentes de que cinco reyes helenísticos fueron realmente retratados con este símbolo iconográfico de poder: Ptolomeo III (282-222 a.C.), Ptolomeo V (210-181 a.C.), Ptolomeo VIII (182-116 a.C.), Antíoco IV (215-163 a.C.), y Antíoco VI (148-138 a.C.) (fig. 8). ${ }^{49}$

Después del año 64 los emperadores romanos se representan en las monedas luciendo la corona radiata de manera recurrente y normalizada. ${ }^{50}$ Así, podemos afirmar que este motivo iconográfico de poder fue asumido después de esa fecha como algo natural, y con monótona regularidad. Si la corona radiata era puramente simbólica, confiriendo divinidad y algún tipo de relación con el Sol en el portador, esto tiene implicaciones tanto para el papel del Sol en la religión imperial romana, como para la relación entre el emperador y el

49. Las monedas con atributos solares de Ptolomeo III (246-222) y sus sucesores, así como las de Antíoco IV (215-163), no son ejemplos de imaginería solar. R. Sмiтн: Hellenistic Royal Portraits, Oxford, 1988, pp. 42-44, con razón rechaza la noción de que los rayos en los retratos reales helenísticos se refieran específicamente a Helios, y se limita a decir que representan el resplandor de la epifanía real-divina.

50. Sobre la relación entre los emperadores y el Sol, véase H. USENER: «Sol Invictus», RhM, LX, 1905, pp. 465-491; R. BERnHARD: «Der Sonnengott auf griechischen und römischen Münzen», Schweizerische Numismatische Rundschau, 25, 1933, pp. 245-298; A. AlFöLDI: «Insignien und Tracht der römischen Kaiser», JdI, 40, 1935, pp. 107-108; H. L'OrANGE: «Sol Invictus Imperator», SymbOslo, 14, 1935, pp. 86114.; A. NoCK: «The emperor's divine Comes», JRS, 1947, 37, pp. 102-116.; R. BRILlianT: Gesture and Rank in Roman Art, Memoirs of the Connecticut Academy of Arts and Sciences XIV, 1963, New Haven, pp. 208211; E. Kantorowicz: «Oriens Augusti - Lever du Roi», DOP, 17, 1963, pp. 117-178; S. MaCCormaCK: «Change and continuity in late antiquity: the ceremony of the Adventus», Historia, 21, 1972, pp. 721-752; R. TURCAN: «Le culte impérial au III siècle», ANRW II, 16.2, 1978, pp. 946-1084; P. BASTIEN: «Couronne radiée et buste monétaire impérial. Problèmes d'Interprétation», en: J. Quaegebur (ed.), Studia Paulo Naster oblata, Leuven, 1982, pp. 263-272; M. Bergmann: Die Strahlen der Herrscher. 


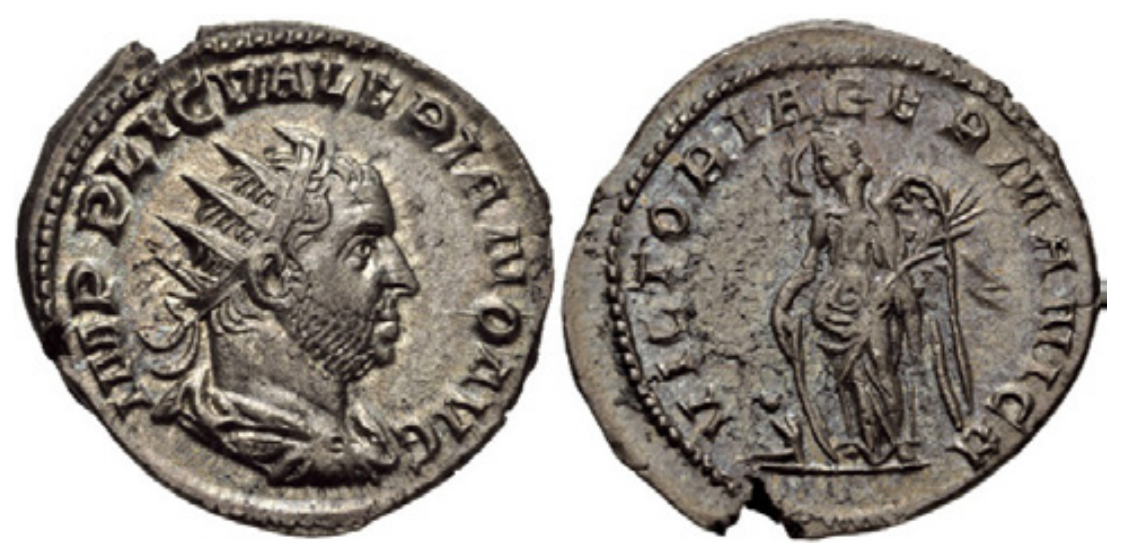

Fig. 9. Moneda da Valeriano. En el reverso se puede ver una alegoría de la Victoria germánica de pie. Primera emisión del 253

Senado. ${ }^{51}$ No podemos - de manera concluyente- suponer que todos los emperadores estaban igualmente interesados en la simbología del Sol, e igualmente dispuestos a incidir en la prerrogativa del Senado para otorgar la condición de divus al emperador de manera póstuma. Estas cuestiones están relacionadas con factores importantes del contexto y de visión. En las monedas imperiales romanas, la corona radiata con cintas es usada por Augusto a título póstumo, por Nerón desde el año 64, y luego regularmente por todos los emperadores romanos que viven de Vespasiano a Constantino (fig. 9). ${ }^{52}$ Lo que se desprende de esto es que todos los elementos y atributos representados comúnmente con bustos imperiales fueron utilizados como elementos estándares de la

51. Los especialistas han insistido en la exclusión del Sol de la corriente principal de la religión romana. En una serie de artículos, por ejemplo, J. Fontenrose: «Apollo and Sol in the Latin poets of the first century B.C.», TAPhA, 70, 1939, pp. 439-455; «Apollo and the Sun God in Ovid», AJPh, 61.4, 1940, pp. 429444; «Apollo and Sol in the Oaths of Aeneas and Latinus», ClPhil, 38.2, 1942, pp. 137-138, argumentó que el Sol y Apolo aún no fueron identificados entre sí en el s. I a.C. Es instructivo leer sus intentos de conciliar esta posición con, por ejemplo, la alternancia entre el Sol y Apolo en el Carmen Saeculare de Horacio. En la connotación peyorativa del sincretismo, A. FELDTKELLER: «Synkretismus und Pluralismus am Beispiel von Palmyra», Zeitschrift für Religions- und Geistesgeschichte, 48.1, 1996, pp. 20-38. Una excelente discusión sobre este tema se puede encontrar en S. PRICE: «Gods and Emperors: The Greek Language of the Roman Imperial Cult», Journal of Hellenic Studies, 104, 1984, pp. 79-95. M. CLAUss: op.cit., pp. 17-38, amplia e ilustra en qué medida aún persisten estos problemas 15 años después.

52. Con anterioridad, en un pequeño número de monedas locales, Helios también se representa con un bastón largo, ya sea apoyándose en él, o al hombro, P. MAtern: Helios und Sol, pp. 93-94. La ceca romana imperial emitió una serie de monedas entre 199 y 210 que podían representan al Sol con el globo, P. Matern: Helios und Sol, p. 303. Aunque no existe unanimidad en que estas monedas estén presentando al Sol y S.. Berrens: Sonnenkult und Kaisertum von den Severern bis zu Constantin I. (193-337 n. Chr.), Historia Einzelschriften 185, Stuttgart, 2004, pp. 43-44, sostiene que la figura representada es Caracalla. En la mayoría de los casos, la corona radiata es realmente difícil de distinguir. Los otros atributos, el globo y lanza, son comunes a muchas figuras y muy raros para el Sol (lanza). 
iconografía imperial. La realidad, por tanto, es la característica primaria del contexto en el que se producen este tipo de coronas. En otras palabras, la imagen, que representa claramente la corona radiata como objeto real, se ve reforzada por el contexto en la medida en todos los demás atributos comunes de bustos imperiales son también objetos reales. Esto sugiere fuertemente que el espectador romano supiese interpretar la corona radiata como un atributo iconográfico que realmente existió como parte de la regalía imperial.

En relación a la naturaleza e interpretación de la corona radiata, todavía no es posible establecer certezas absolutas. Bergmann argumenta enérgicamente en favor de la interpretación de la corona radiata como un atributo puramente simbólico, honorario de connotaciones solares y divinas. La autora reconoce que este argumento está en contradicción con las representaciones de la corona radiata imperial como un objeto real, que consiste en una corona alrededor de la cabeza, a la que los puntos del metal se adjuntan como rayos, y que fue fijada en la parte posterior de las cintas..$^{53}$ Esta representación se mantuvo escrupulosamente durante los tres siglos que los emperadores fueron retratados con esta iconografía solar de la irradiación. Esta es una interpretación que difiere de la de Alföldi, ${ }^{54}$ que sugiere que la corona radiata era en realidad una corona real helenística, usada por los emperadores, de la que emanaban rayos simbólicos que denotaban la divinidad. El sentido común nos sugiere que el atributo característico del Sol -me refiero a los rayos que emanan de la corona radiata - añada un significado adicional en estas circunstancias, por lo que es probable que para los ojos de un espectador romano la identidad predeterminada de un busto de un joven imberbe con el pelo largo y rayos deban identificarse con el Sol. Sin embargo, la presencia de los rayos no es indispensable. Hay ejemplos de bustos sin ningún rastro visible de rayos que con casi total seguridad representan al Sol, en vista del contexto de su hallazgo, y hay bustos con los rayos que son claramente retratos que no tienen nada que ver con el Sol.

La iconografía de poder asociada a la corona radiata en la imagen imperial presupone también autoridad espiritual, como visualización deliberadamente idealizada de la belleza Apolínea-Augusta. Por ejemplo, a través de la desnudez heroica que se manifestó en una colosal estatua de bronce dorado de Constantino en el Foro de Constantinopla (fig. 10). ${ }^{55}$ Aunque los detalles de la iconografía de la estatua son inciertos (y seguirán siendo discutidos), era definitivamente una imagen imperial grandiosa en la tradición de retratos helenísticos, exhibiendo el estado humano anterior del gobernante (a través de

53. M. Bergmann: Die Strahlen der Herrscher, pp. 116-117, analiza todas las representaciones bidimensionales de la corona radiata. También tenemos un pequeño número de bustos de mármol con una corona radiata de algún tipo, que consiste en una banda bastante gruesa alrededor de la cabeza, justo por encima de las orejas, en la que se perforaron agujeros para mantener los rayos.

54. A. ALFÖLDI: «Insignien und Tracht der römischen Kaiser», JdI, 40, 1935, p. 46.

55. R. Sмітн: «Roman Portraits. Honours, Empresses, and Late Emperors», JRS, 75, 1985, p. 202. 


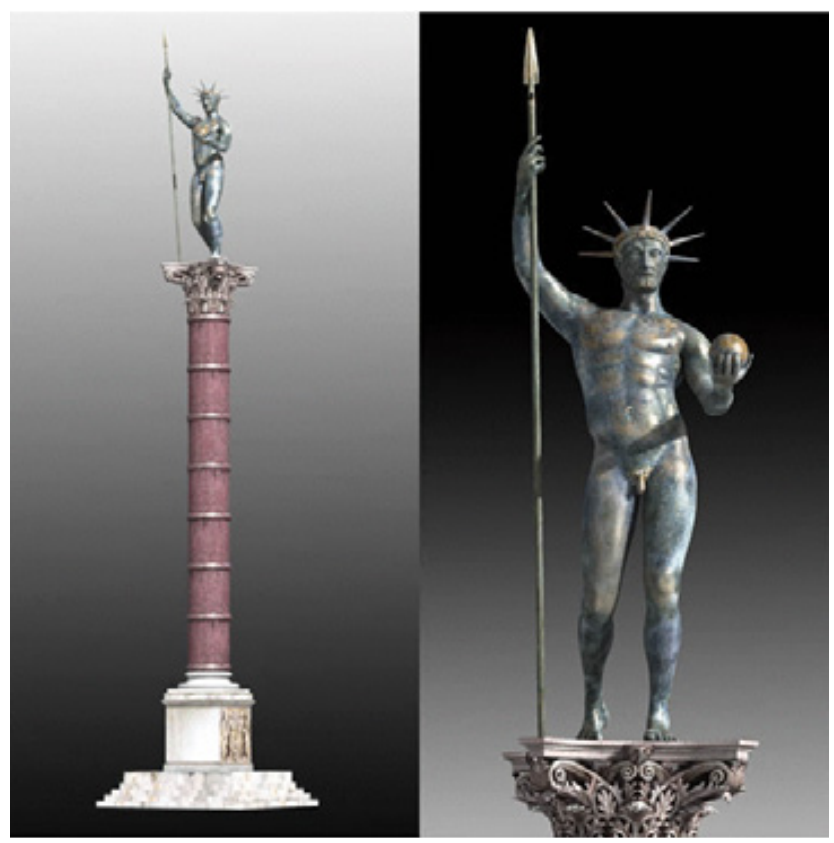

Fig. 10. Estatua de Constantino en su columna en Constantinopla, reconstrucción realizada por Jonathan Bardill (Constantine Divine Emperor of the Christian Golden Age, Cambridge University Press, 2011)

atributos tales como la lanza).$^{56}$ Esta imagen mostraba, de manera plausible, las asociaciones con el dios Sol-Helios a través de una corona radiata. Iconográficamente, evocaba este tipo de corona que fue añadida a la estatua de Octavio en el recinto de Apolo en el Palatino, en una fecha incierta después de la muerte de Augusto. Esta estatua, que se levantaba sobre una columna adornada con las proas y las anclas de los barcos, había sido fijada para conmemorar la victoria en Actium. El monumento contaba con la presencia de la corona radiata, que ya formaba parte de la iconografía imperial desde la acuñación de monedas bajo Vespasiano y Tito: los rayos emergían en los ángulos de la cabeza de Augusto, y la estatua desnuda prefigura así la de Constantino en la columna de pórfido en Constantinopla. ${ }^{57}$

56. D. Wright: «The True Face of Constantine the Great», Dumbarton Oaks Papers, 41, 1987, pp. 493-450.

57. Como afirma A. Cadenas GonzÁlez: «Contaminaciones paganas en la imagen de los primeros emperadores cristianos en la nueva roma: el caso de Constantino», ETF, Serie II, 22, 2014, p. 73, se pueden establecer paralelismos entre esta iconografía y la escultura de Nerón junto al Coliseo, haciendo referencia a una nueva edad de oro de prosperidad, seguridad y libertad bajo el gobierno del Dios Sol. J. BARDILL: Constantine, Divine Emperor of the Christian Golden Age, Cambridge, 2011, pp. 47-48; G. FowdEN: «Constantine's Porphyry Column: The Earliest Literary Allusion», JRS, 81, 199, pp. 119-131. 


\section{Conclusiones}

Los datos presentados permiten afirmar que la cultura visual romana muestra la similitud entre la corona radiata y el simbolismo de la radiación solar, lo que permite al artista asimilar el retrato imperial con diferentes significados simbólicos derivados directamente del tipo de imagen del Sol. Tales usos secundarios y metafóricos de la corona radiata nos llevan a un nuevo nivel de significado y comunicación visual. Lo que hemos establecido es que la corona radiata no fue solo un símbolo solar o divino. Por tanto, no se puede asumir automáticamente que cualquier tipo de rayos indicase en la cultura visual romana una referencia al Sol. La corona radiata era un objeto real, cuidadosamente diferenciado de las convenciones visuales relacionadas con la luz simbólica y/o divina. Tenía sus propios significados y connotaciones, más allá de sus conexiones simbólicas con el Sol. Durante los primeros cincuenta años de su uso, fue una corona honoraria asociada exclusivamente con Augusto. Sin embargo, Desde Nerón en adelante, su uso evolucionó rápidamente en una corona honoraria asociada con el poder (invictus), a través de sus connotaciones cósmicas y su simbolismo.

Hemos de suponer que el espectador romano no tendría problemas a la hora de identificar esta iconografía. Estas imágenes fueron usadas raramente como objetos directos de culto o veneración, y mucho más regularmente como encarnaciones visuales de conceptos abstractos como el orden divino o la estabilidad cósmica. Estos conceptos fueron transmitidos a través de una imagen antropomorfa de un joven con el atributo específico de la corona radiata. El marco teórico de estas imágenes nos revela un aspecto semiótico particular del arte romano. Cuanto más estructurado es el sistema visual de significación de las imágenes, más probable es que sus significados sean una cuestión de convención social. En las imágenes del Sol, hemos podido apreciar un alto grado de consistencia en las reglas que rigen su iconografía. Incluso aspectos como la representación de la luz divina estaban gobernados por reglas estrictas que se mantuvieron vigentes durante siglos, prescribiendo claramente qué convenciones iconográficas para la luz divina eran adecuadas para determinadas figuras. Así pues, las convenciones visuales relativas a la corona radiata ponen de manifiesto que fue un símbolo augusto e imperial, más que solar y divino. La importancia de lo visual en el mundo romano se ilustra no solo por la estabilidad de la iconografía del Sol, sino también por el hecho de que sus reglas eran conocidas y seguidas en todo el Imperio. 
